\title{
Implementation of an Embedded Controlled High Efficiency Improved Boost Converter for Solar Installation System
}

\author{
A. Kalirasu ${ }^{\mathrm{a} *}$, Shubhransu Sekhar Dash ${ }^{\mathrm{b}}$ \\ ${ }^{a}$ Department of Electrical and Electronics Engineering, Sathyabama University, Chennai-600119,T.N, India \\ ${ }^{b}$ Department of Electrical and Electronics Engineering, SRM University, Chennai-603203,T.N, India
}

\begin{abstract}
Nowadays solar power generation is considered the best one compared to the conventional power generation system because it is clean and does not emit hard gases to the environment. This paper proposes a new topology for photovoltaic DC to DC converter with high gain and efficiency under wide input voltage range. The topology study of open loop and closed loop systems with high gain step-up conversion and step increase in input voltage are proposed. An improved DC to DC boost converter is modelled and simulated using matlab and it is implemented using embedded controller. This converter provides the constant output voltage irrespective of the PV panel output and load. The simulation and experimental results of this system are presented and compared. The performance of the converter is also compared with the conventional boost converter. This comparison reveals that the proposed converter system has the advantages of high gain and high efficiency with the minimum number of components.
\end{abstract}

Keywords: Improved boost converter, embedded controller, solar cell

\section{Introduction}

Renewable and sustainable energy sources such as photovoltaic (PV) and fuel cells (FC) require power electronic conditioning [1]. Recently, the installation of PV generation systems is rapidly growing due to concerns related to environment, global warming, energy security, technology improvements and decreasing costs. PV generation system is considered as a clean and environmentally-friendly source of energy. The main applications of PV systems are in either standalone or grid connected configurations. Standalone PV generation systems are attractive as indispensable electricity source for remote areas [2]. However, PV generation systems have two major problems which are related to low conversion efficiency of about $9 \%$ to $12 \%$ especially in low irradiation conditions and the variation of amount of electric power generated by PV arrays continuously with weather conditions. Therefore, research works are carried out to increase the efficiency of the energy produced from the PV arrays [3]. The output of the FC or PV cells is typically an unregulated low-level DC voltage that needs to be stepped up to a regulated higher level, for many potential practical applications, and boost converter stages are employed for this purpose. In many applications, the use of a transformer can provide increased output/input voltage gain, as required [4]. However, there are a number of applications where transformer-less power electronic energy converter systems could potentially offer significant advantages, including cost and converter size reduction.

The DC to DC or boost converter is the front-end component connected between the PV array and the load. The conventional boost converter may cause serious reverse recovery problem and increase the rating of all devices. As a result, the conversion efficiency is degraded and the electromagnetic interference problem becomes severe under this situation. To increase the conversion efficiency, many modified step-up converter topologies have been investigated by several researchers [5]. Voltage clamped

\footnotetext{
* Manuscript received July 25, 2012; revised August 25, 2012.

Corresponding author. Tel.: +91-9884360423; E-mail address: akalirasu@yahoo.co.in.
} 
techniques have been incorporated in the converter design to overcome the severe reverse-recovery problem of the output diodes [6]. A novel high-efficiency step-up converter was proposed in [7]. A transformer-less boost converter with high gain and low current ripple for fuel cell applications was discussed in [8]. A new controller scheme to control the boost converter for photovoltaic (PV) power generation system was discussed in [9].Design and application for PV generation system using a softswitching boost converter with SARC was discussed in [10].

The above literatures do not deal with the embedded implementation of improved boost converter system for solar installation. The limitations of the conventional boost converters are analyzed and the conceptual solution for high step-up conversion is proposed in this paper. This work makes an attempt to implementation of the improved boost converter using PIC16F84A controller.

\section{Improved Boost Converter}

In the boost converter, load voltage $V_{0}$ is more than the source $V_{s}$. It is a class of switching-mode power supply containing at least two semiconductor switches (a diode and a transistor) and at least one energy storage element. Filters made of capacitors in combination with inductors are normally added to the output of the converter to reduce output voltage ripple. By implementing the pulse width modulation (PWM) techniques on the boost converter, a stable output voltage from a non stable input voltage can be obtained by changing the duty cycle of the switched input pulse. In this paper, closed loop control of an improved boost converter design is presented by modifying the voltage gain equation which is a function of the duty cycle. The voltage gain can be increased by adding more clamping devices so as to deal with the severe reverse recovery problem. Fig. 1 shows the circuit diagram of the proposed boost converter consisting of an inductor in the source side (L), clamping diodes, D1, D2, capacitor C2 used to form a regenerative circuit to sink the reverse recovery, high voltage capacitor, $\mathrm{C} 1$ and an output filter circuit formed with diode, $\mathrm{D} 0$ and capacitor, $\mathrm{C} 0$.

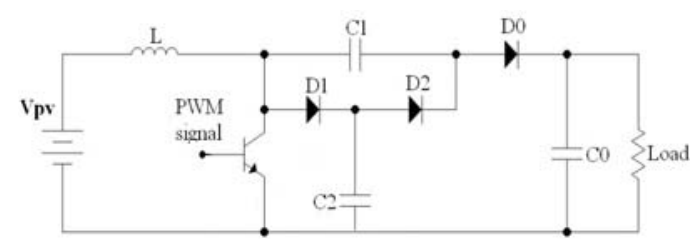

Fig. 1. Improved boost converter.

The average output voltage is given as

$$
V_{0(\text { avg })}=\frac{V_{s}}{2} \sqrt{D(1-D)^{2}}
$$

where $V_{s}$ is the input voltage, $D$ is the duty cycle ratio. The load value is

$$
\begin{aligned}
& R=V^{2} / P \\
& I_{0}=V_{0} / R
\end{aligned}
$$

\section{Simulation Results}

Simulation is done using Matlab and the results are presented. The Simulink model of an improved DC to DC boost converter for solar installation system is shown in Fig. 2 (a). Simulation of the improved boost converter was carried out with the following parameters. $V_{\text {in }}=12 \mathrm{~V}$ to $17 \mathrm{~V}, V_{0}=60 \mathrm{~V}, L=5 \mathrm{mH}$, $C=2000 \mu \mathrm{F} \& 30 \mathrm{mF}$, Duty cycle ratio $=65 \%$ and $R_{L}=10 \Omega . V_{\text {in }}$ is applied as input voltage in normal condition as shown in Fig. 2 (b). $V_{\text {in }}$ of 17 volts is applied as input while assuming external disturbance in the PV panel. The driving pulse of the MOSFET is shown in Fig. 2 (c). The duty cycle ratio of the pulse is $65 \%$. The output current is shown in Fig. 2 (d) which is 6 A. The DC output voltage is shown in Fig. 2 (e). The steady state value of output voltage is $60 \mathrm{~V}$. 


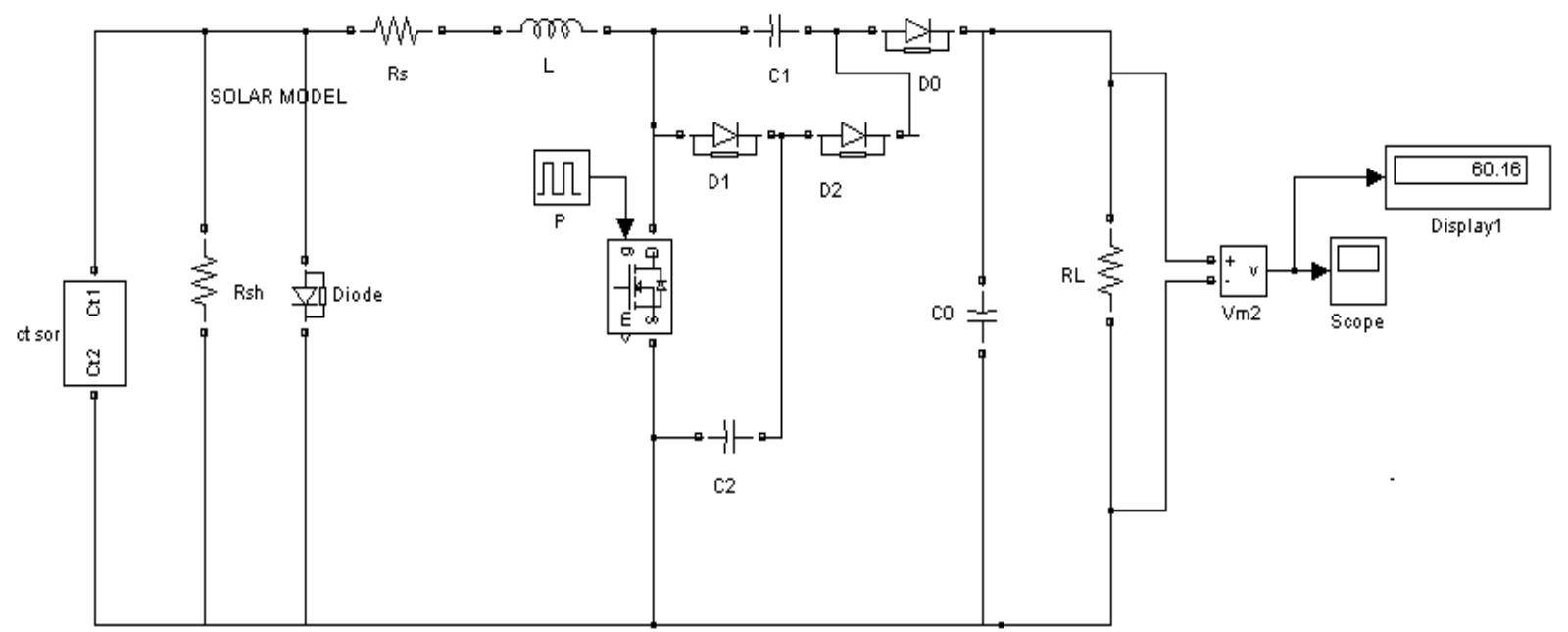

(a)

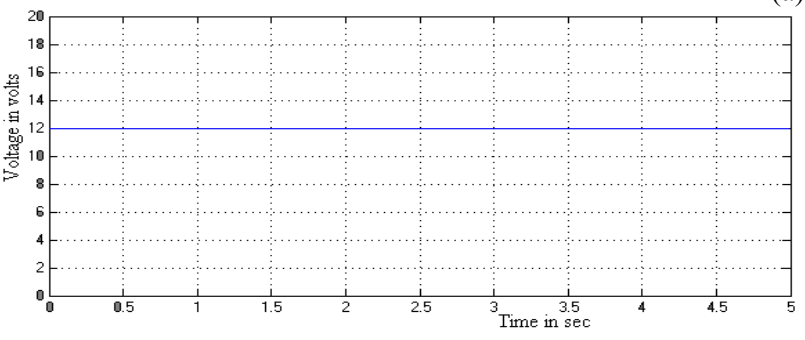

(b)

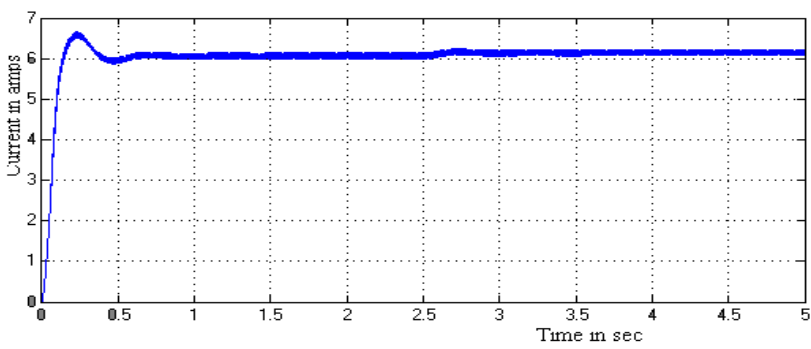

(d)

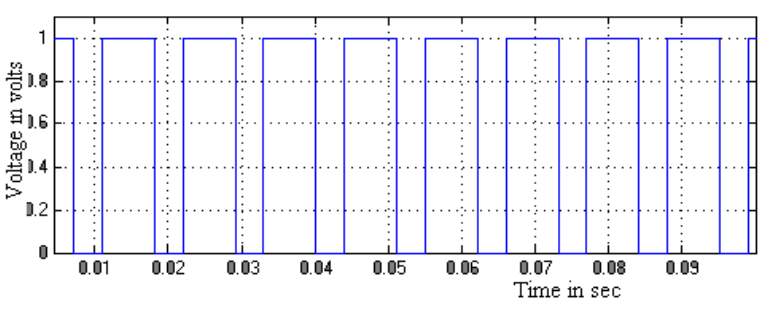

(c)

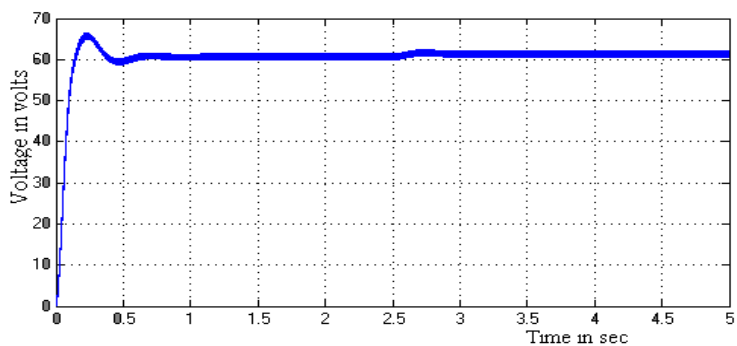

(e)

Fig. 2. Improved DC to DC boost converter with waveforms: (a) converter, (b) input voltage, (c) driving pulses for switch, (d) output current, and (e) DC output voltage.

The open loop system with disturbance is shown in Fig. 3 (a). In this open loop system an external disturbance of $5 \mathrm{~V}$ is applied with the input voltage at $2.5 \mathrm{sec}$. The input and output voltages of the open loop system with disturbances are shown in Fig. 3 (b) and Fig. 3 (c) respectively. $12 \mathrm{~V}$ is applied as input till $2.5 \mathrm{sec}$ so that the converter produces an output voltage of $60 \mathrm{~V}$. At $2.5 \mathrm{sec}$, with the $12 \mathrm{~V}$ input voltage, $5 \mathrm{~V}$ is added as disturbance in the input side. At $2.5 \mathrm{sec}$, the output voltage starts to increase from $60 \mathrm{~V}$ to $88.28 \mathrm{~V}$ for the $17 \mathrm{~V}$ input.

The closed loop system with disturbance is shown in Fig. 4 (a). The closed loop system is designed to provide constant output voltage for a step change in output voltage. The input and output voltages of the closed loop converter with disturbance are shown in Fig. 4 (b) and Fig. 4 (c), respectively. Till $2.5 \mathrm{sec}$ the output voltage of the converter is $60 \mathrm{~V}$ for the input of $12 \mathrm{~V}$. At $2.5 \mathrm{sec}$, the input voltage increases from $12 \mathrm{~V}$ to $17 \mathrm{~V}$ due to the external disturbance. Hence the output voltage rises beyond $60 \mathrm{~V}$. Output voltage is sensed and it is compared with a reference voltage. Then the error is processed by a PI controller. The output of PI controller adjusts the pulse width to maintain the constant output voltage of $60 \mathrm{~V}$. Thus the output voltage reduces and reaches the steady state set value of $60 \mathrm{~V}$ at $2.8 \mathrm{sec}$. In the closed loop system, the response of the system is very faster than the open loop system. The delay time, rise time and peak time are very smaller than open loop system specification. It reaches its steady state very quickly. 


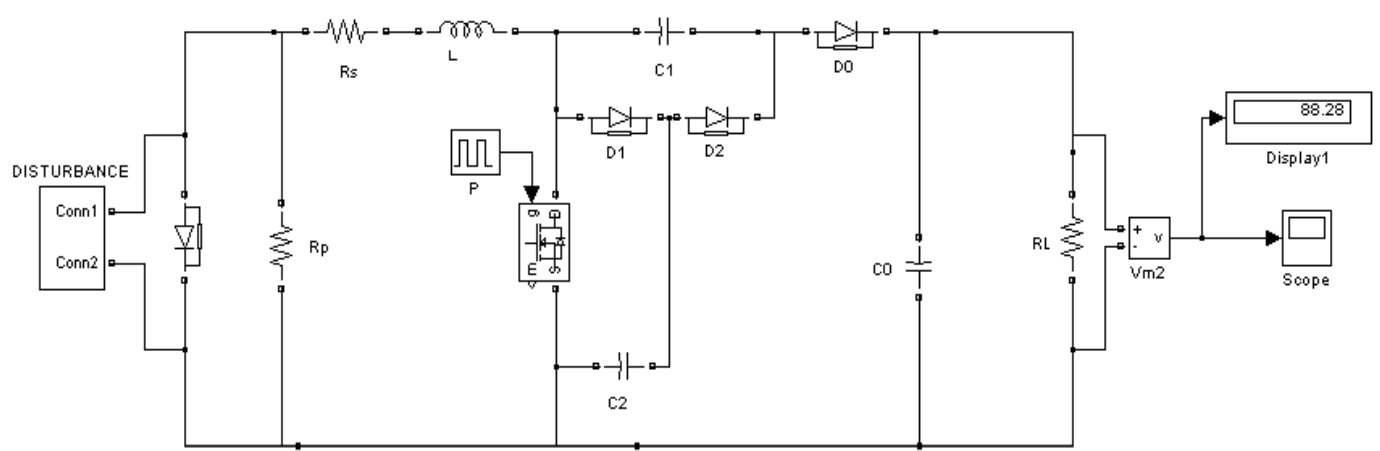

(a)

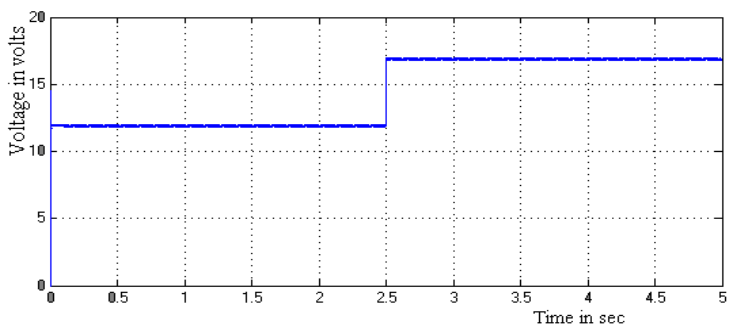

(b)

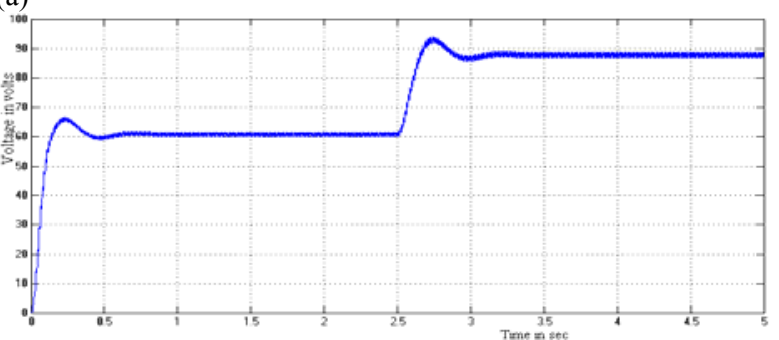

(c)

Fig. 3. Open loop system with disturbance: (a) converter, (b) input voltage and (c) output voltage.

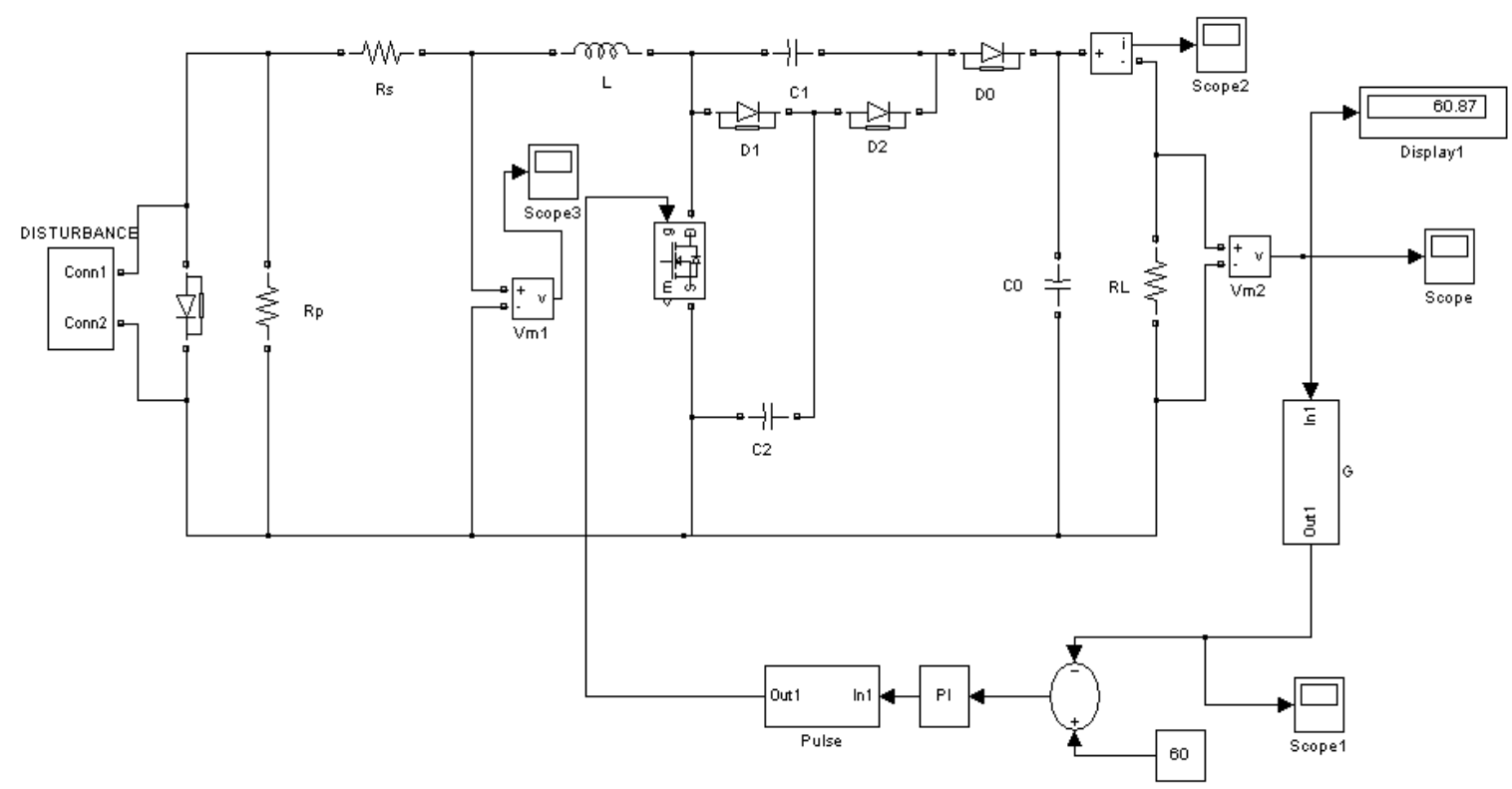

(a)

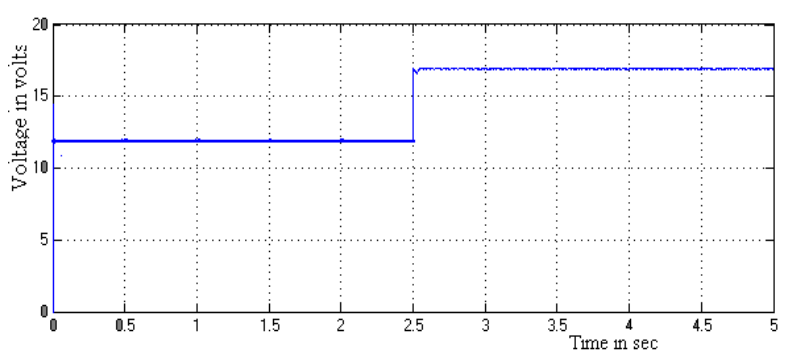

(b)

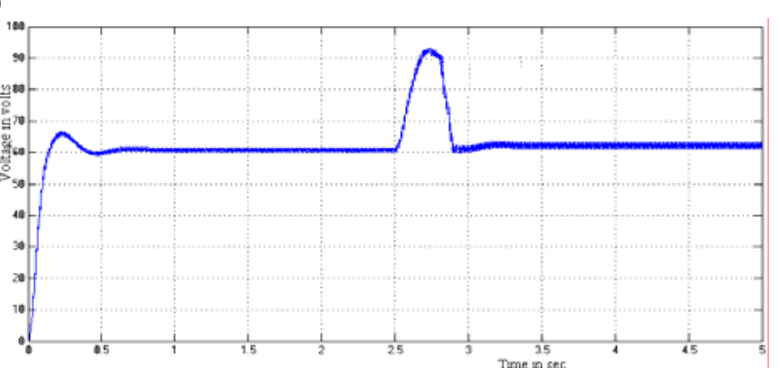

(c)

Fig. 4. Closed loop system with external disturbance: (a) converter, (b) input voltage and (c) output voltage.

\subsection{Time response analysis}

The time response specifications of the output voltage are analyzed. Delay time is $0.063 \mathrm{sec}$, Rise time is $0.142 \mathrm{sec}$, peak time is $0.143 \mathrm{sec}$, settling time is $0.38 \mathrm{sec}$ and \% of maximum peak overshot is $9.25 \%$. 


\subsection{Performance comparison analysis}

The performance of the proposed boost converter is compared with the performance of the conventional boost converter and the comparison is presented in Table 1 . The proposed and conventional converter performances in open loop system are analysed for different input voltages. However, in closed loop system the converter maintains a constant output voltage for step change in input voltage.

Table 1. Performance comparison

\begin{tabular}{|c|c|c|c|c|}
\hline \multirow{2}{*}{$\begin{array}{l}\text { Input } \\
\text { voltage } \\
\text { (V) }\end{array}$} & \multicolumn{2}{|c|}{ Output voltage (V) } & \multicolumn{2}{|c|}{ Efficiency (\%) } \\
\hline & $\begin{array}{c}\text { Conventional } \\
\text { boost converter }\end{array}$ & $\begin{array}{l}\text { Improved boost } \\
\text { converter }\end{array}$ & $\begin{array}{c}\text { Conventional } \\
\text { boost converter }\end{array}$ & $\begin{array}{c}\text { Improved } \\
\text { boost converter }\end{array}$ \\
\hline 10 & 27.53 & 49.87 & 82.79 & 92.11 \\
\hline 12 & 33.73 & 60.16 & 83.3 & 92.98 \\
\hline 14 & 38.89 & 69.06 & 83.67 & 93.23 \\
\hline 16 & 44.05 & 79.61 & 83.95 & 93.62 \\
\hline 18 & 50.15 & 90.5 & 83.6 & 93.93 \\
\hline
\end{tabular}

The input verses output voltage comparison of the proposed and conventional boost converter is shown in Fig. 5. For the input of $12 \mathrm{~V}$, the conventional boost converter can produce $33.73 \mathrm{~V}$ but the proposed converter produces $60.16 \mathrm{~V}$. The input voltage verses output power comparison is shown in Fig. 6 and input voltage verses efficiency comparison is shown in Fig. 7. For the input of $12 \mathrm{~V}$, the conventional boost converter can deliver an output power of $112.3 \mathrm{~W}$, but the proposed converter can deliver an output power of $369.3 \mathrm{~W}$. For the same input of $12 \mathrm{~V}$, the efficiency of the conventional boost converter is $83.3 \%$ only but the proposed boost converter can give an efficiency of $92.98 \%$. This is almost $10 \%$ higher than the conventional boost converter efficiency.

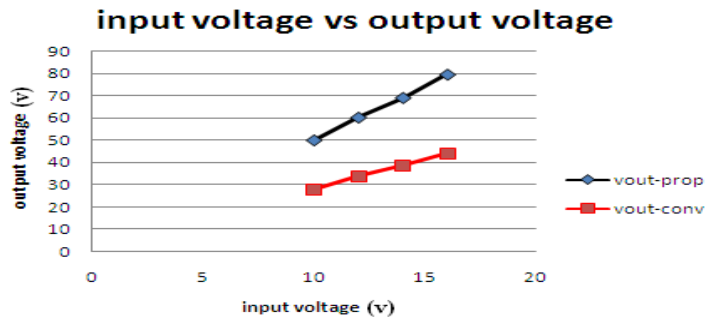

Fig. 5. Input vs. output voltage.

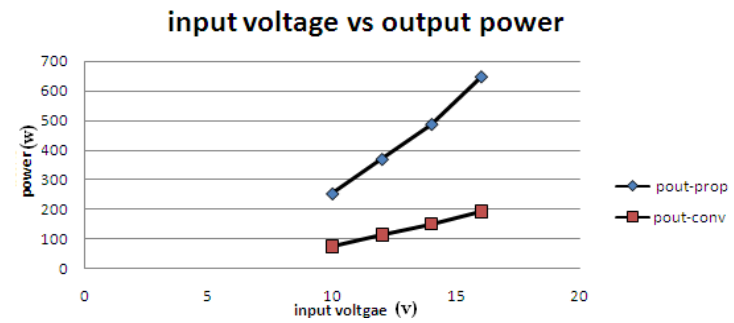

Fig. 6. Input voltage vs. output power.

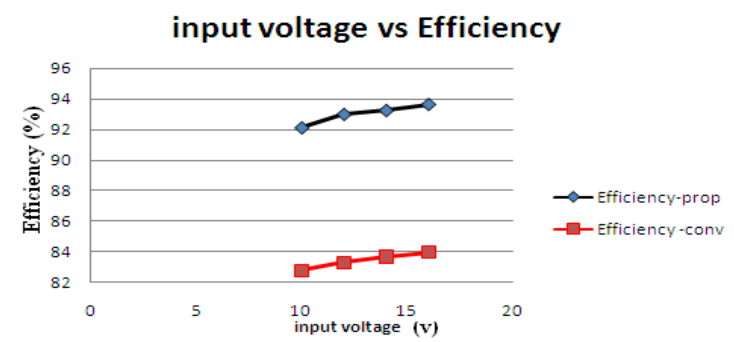

Fig. 7. Input voltage vs. Efficiency.
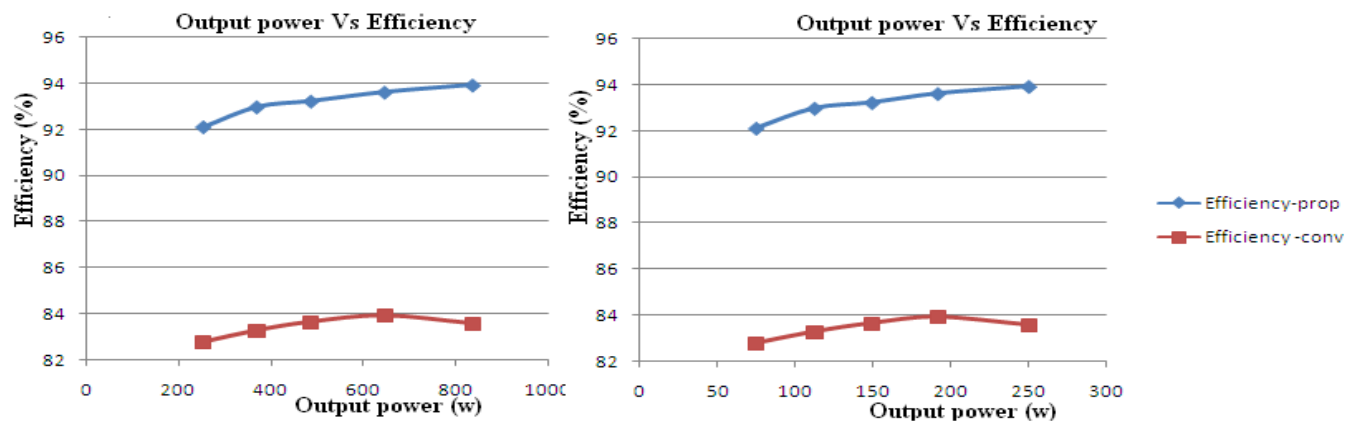

Fig. 8. Output power vs. Efficiency 
The output power verses efficiency comparison is shown in Fig. 8. The conventional boost converter gives efficiency in the range of $83 \%$ but the proposed converter can give an efficiency of $93 \%$.

The above results confirm that the improved boost converter has better performance efficiency than conventional boost converter.

\section{Experimental Results}

In order to verify the circuit operation and confirm the simulation results, a prototype is built and tested in laboratory. The hardware implementation is shown Fig. 9. The solar panel input is applied to the converter circuit. The switches are turned on and off by the pulse driver circuit. Display of output voltage is shown in Fig. 10. For the input voltage of $12 \mathrm{~V}$ (without external disturbance) and 17V (with external disturbance) the output voltage of the improved boost converter is $59.2 \mathrm{~V}$ which is closely in line with the simulation result. The output is free from ripple which is shown in Fig. 11.

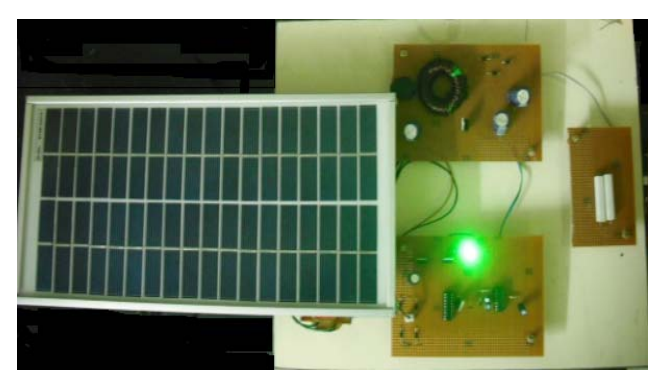

Fig.9. Hardware Circuit

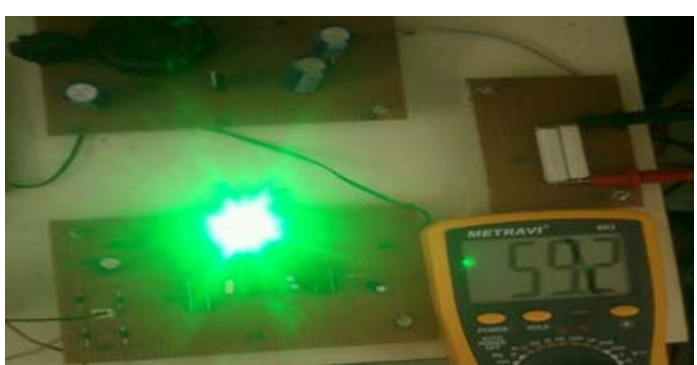

Fig. 10. Display of the output voltage

Fig.11.Oscillogram of Output voltage

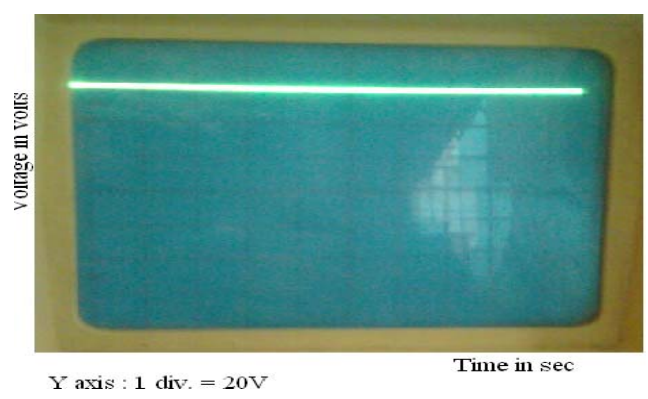

\section{Conclusion}

In this paper, an improved boost converter is designed, developed and implemented for a solar installation system. The converter topology is selected after researching and comparing various topologies. The open loop and closed loop system of the converter is presented. The designed circuit is modelled and simulated using matlab/Simulink and it was implemented using embedded controller and lab tested. The simulation and experimental results of this system are compared with the conventional boost converter, and its time response analysis was made. This improved boost converter can continuously provide constant output voltage even with disturbance at the input voltage side. It was observed that the proposed improved boost converter system has the advantages of high efficiency, fast response, and low ripple content and reduced number of switching component. The experimental results confirmed that the improved DC to DC boost converter gives better performance efficiency than conventional boost converter.

\section{References}

[1] Blaabjerg F, Chen Z, Kjaer SB. Power electronics as efficient interface in dispersed power generation systems. IEEE Trans. Power Electronics, 2004; 19(5):1184-1194. 
[2] Nakayama H. Stand-alone photovoltaic generation system with combined storage using lead battery and EDLC. In: Proc. of the Power Electronics and Motion Control Conference, 2008:1877-1883.

[3] Salas V, Barrado A, Lazaro A. Review of the maximum power point tracking algorithms for stand-alone photovoltaic systems. Solar Energy Materials \& Solar Cells, 2006:1555-1578.

[4] Xue Y, Chang L, Kjaer SB, Bordonau J, Shimizu T. Topologies of single-phase inverters for small distributed power generators: an overview. IEEE Trans. PowerElectronics, 2004; 19(5):1305-1314.

[5] Wai RY, Duan L, Jheng K-H. High-efficiency bidirectional dc-dc converter with high-voltage gain. IET Power Electronics, 2012; 5(2):173-184.

[6] Wai RY. High-performance stand-alone photovoltaic generation system. IEEE Transaction on Industrial Electronics, 2007; 55:240-250.

[7] Tseng KC, Liang TJ., Novel high-efficiency step-up converter. IEE Proc. Electr. Power Appl., 2004; 151(2):182-190.

[8] Park C, Yang J, Choi S, Nam S. A transformer-less boost converter with high gain and low current ripple for fuel cell applications. In: Proc. of Korean Institute of Power Electronics Conf., 2006:348-351.

[9] Khatib TNT, Mohamed A, Amin N. A new controller scheme for photovoltaics power generation systems. European Journal of Scientific Research, 2009; 33(3):515-524.

[10] Park SH, Cha GR, Jung YC, Won CY. Design and application for PV generation system using a soft-switching boost converter with SARC. IEEETransaction on Industrial Electronics, 2010; 57(2):515-522. 